\title{
What type of faculty member interacts with what type of firm? Some reasons for the delocalisation of university-industry interaction
}

This version: $13 / 04 / 07$

\begin{abstract}
While there is significant interest in improving university-industry interaction, literature on the university side has tended not to focus on the characteristics of the personnel involved and has largely ignored the issue that there are differences between types of faculty member in their degrees of interaction. This question is especially relevant at regional level, as those faculty members who do interact with industry may show a preference for firms that are larger and technologically superior to those in the region. Most analysts, though, have tended to focus on the national level, particularly on those countries at the forefront of technological innovation. In the absence of any formal theory, we propose a two-step method to formulate the hypothesis that only selected faculty members interact with selected firms. First, we identify the type of faculty member who interacts with firms. Second, we examine whether this type of faculty member interacts with every type of firm. A test sample is drawn from the Valencian Community of Spain, a region with low absorptive capacity, where firms may show undesirable properties for university interaction. The results allow us to challenge the view that certain individual universities may show a higher propensity for interaction once we take into account differences between the individual characteristics of their faculty members. We also claim that in a region like the Valencian Community, faculty members who usually participate in contracts (male, holding an administrative position) do so mainly with larger firms, but not with firms from their own region, where they find lower technological standards. This partly explains the delocalisation of university-industry interaction.
\end{abstract}

Keywords: university-industry interaction

\section{Introduction}

There is abundant theoretical argumentation and empirical evidence of the influence of technological innovation on economic development. It is therefore consequent that economic science opened a body of analysis on technological innovation, studying its determining factors. Initially focused within the industrial world (Griliches, 1958, Scherer 1965, Mansfield, 1968), it has given rise to much empirical work on the quantification of the contribution of university R\&D. Studies have found a relevant link between science and industry (Narin and Noma, 1985; Narin et al., 1997) and between academic R\&D and patents or other measures of innovation (Jaffe, 1989, Acs et al., 1991, Mansfield, 1991). 
However, these approaches scarcely deal with the way in which university R\&D reaches the industrial world. They rather suggest that it takes place spontaneously, beyond control of the individual who intervene, maybe inspired by the linear model of technological innovation (often attributed to Bush, 1945). This line of thought underestimates the idea that some contexts favour the contribution of university R\&D to innovation more than others, as well as the limited use of science by firms from an interactive understanding of the link between knowledge production and innovation (Kline and Rosenberg, 1986).

Several approaches that incorporate ideas from sociology to economics have come to justify that increasing the contribution of university R\&D requires fostering universityindustry interaction (UII): Freeman (1987) and Lundvall (1988) under the perspective of national systems of innovation, Gibbons et al. (1994) with their detection of new Mode 2 of knowledge production, Etzkowitz and Leydesdorff (1996) with their ideas about the Triple Helix model. These approaches differ in the importance granted to universities in the innovation process, but do not question that some degree of interaction with firms should exist.

On the other hand, some studies have insisted on the idea that the traditional view of the contribution of university basic research refers to its direct effects, i.e. the provision of explicit knowledge in the form of tangible results for firms. A more modern view should also take into account the existence of indirect benefits, e.g. increasing useful (mainly tacit) knowledge, training skilled graduates, creating new scientific instrumentation and methodology, forming networks and social interaction, increasing the capacity for scientific and technological problem-solving, creating new firms (Salter and Martin, 2001), providing social knowledge and access to unique facilities (Scott et al., 2002). Even if it is arguable that these benefits are necessarily the outcome of 
university basic research, it is reasonable to assume that the contribution of universities to innovation does not come only from basic research but also from other activities that define the so-called third mission, in addition to teaching and research (Molas-Gallart et al., 2003).

The convenience of the ongoing changes in the institutional settings to maximise UII is therefore put into question, since they do not ensure the maintenance of a broader set of benefits from academic activities. Despite these concerns, the academic reflection privileges some aspects of UII on the university side that leave some gaps in the literature.

First, there are copious studies at institutional level (e.g. Vedovello, 1997; MoraValentin et al., 2004; Marques et al., 2006; Rasmussen et al., 2006) and the scarce studies at individual level have paid more attention to the institutional and input factors than to on the characteristics of the personnel involved (Lee, 1996; D'Este and Patel, 2005), in spite of their great autonomy at public universities to decide whether to engage on interactive activities or not. The literature on scientific production can still provide some insights into the influence of personal characteristics on UII.

Second, most analysis focus case studies of managerial actions leading to increase UII (Marques et al., 2006; Vedovello, 1997; Rasmussen et al., 2006), sometimes measuring and explaining the degree of interaction (Lee, 1996; Mora-Valentin et al., 2004; D'Este and Patel, 2005; Schartinger et al., 2002). They do not specify the kind of firms, assuming that the incentives and possibilities for all faculty members to interact with publicly targeted firms are homogeneous, e.g. with firms matching the average profile in the region. Nevertheless, there is no reason, a priori, why that interaction should not take place with non-targeted firms. We have to take resource to the literature 
on UII from the side of firms to derive ideas about the preference of faculty members for some firms to interact with.

Third, research is usually conducted at country level, for high-tech countries like US (Lee, 1996), Canada (Hanel and St-Pierre, 2006), UK (Vedovello, 1997; D'Este and Patel, 2005), Germany (Schartinger et al., 2002) or Scandinavia (Rasmussen et al., 2006), and occasionally for low-tech countries like Spain (Mora-Valentin et al., 2004) or Portugal (Marques et al., 2006). The analysis at regional level is as important, though, since UII may not play the same role in all of them (Buesa et al., 2006), but it has not merited so much interest, especially in low-tech regions, with pioneering exceptions like the case of Aragon in Spain (Sanchez and Pastor, 1995). The call for attention in this kind of regions is appealing, as their firms may show undesirable properties for interaction, e.g. small size, traditional orientation, low engagement in R\&D activities or scarce human capital.

This contribution will try to bridge the existing gap in the literature by providing some theoretical reflection on UII from the academic side at individual level, and by focusing not only on the degree of interaction of faculty members but also on the type of firms they are more eager to interact with. It will also propose a two-step method to test the hypothesis that only selected faculty members interact with selected firms. First, we will identify the type of faculty member who interacts with firms. Second, we examine whether this type of faculty member interacts with every type of firm.

Section 2 reviews the literature to this end. In Section 3 we explain the methodology and data used to test the hypothesis, based on the case of the Valencian Community of Spain, which we define as a region with low absorptive capacity, where there is evidence that faculty members will engage into UII provided that they exchange relevant scientific knowledge (Azagra et al., 2006), and for this reason they may not 
restrict interaction to firms in the region. Now we explore in some more detail the characteristics of firms with which faculty members interact in order to better understand why they may not find them in the region. Section 4 shows the results and Section 5 offers the conclusions.

\section{Review of the literature}

This section explores the existing literature on the determinants of UII according to our to our two-step method to formulate the hypothesis that only selected faculty members interact with selected firms. First, we will identify the type of faculty member who interacts with firms. Second, we examine whether this type of faculty member interacts with every type of firm.

\subsection{What type of faculty members tends to interact more with firms?}

We divide the characteristics of faculty members into institutional and input factors on the one hand and personal characteristics on the other. The following sections are divided accordingly.

\subsubsection{Faculty members' institutional and input factors}

We focus on the influence of type of university, type of discipline and dedication to R\&D.

Lee (1996) finds a negative relation between university prestige and support for the objectives of collaboration with firms, which he considers a proxy for actual UII. However, although they use firms as the observation unit, Mora-Valentin et al. (2004) find a significant effect of the perceived reputation of research organisations (mostly universities) on the perceived success of participation in cooperative agreements. To add complexity to this issue, D'Este and Patel (2005) show that their university dummy 
variables are not significant in determining the variety of interaction. Taking these considerations into account, it is not advisable to impose an a priori concept on the relation between university prestige and the degree of UII. Actually, it is not at odds to be one of the oldest universities in Europe and to be qualified as an entrepreneurial university (Marques et al., 2006). Moreover, "despite different internal and external conditions, the challenges related to commercialisation and the new venture generation remain much the same" at several universities where case studies show some success of commercialisation efforts (Rasmussen et al., 2006).

Lee (1996) also finds a positive relation between faculty members in engineering and technological disciplines and the support for the objectives of collaboration with firms. However, Schartinger et al. (2002), using the link between scientific disciplines and the economic sector as the unit of observation, find a greater propensity to interact in natural, technical, farming and economic sciences than in medicine, other social sciences and humanities. That is to say, unlike Lee's study, engineering does not stand alone at the top nor do social sciences stand alone at the bottom. D'Este and Patel (2005) find their disciplinary dummy variables significant in determining the variety of interaction, but they do not report the econometric effect of each dummy variable. In any case, this again makes caution recommendable before positing possible relations between variables.

Finally, Lee (1996) finds some evidence, through Pearson tests, that the greater the dedication to $R \& D$ activities, the greater the support for the objectives of collaboration with firms will be, but the evidence is no longer significant when he includes this dedication as an explanatory variable in an econometric model together with the previous variables (type of university, disciplines). However, it is possible to argue that the difference between Lee's virtual measure of UII and actual UII is sensitive to 
dedication to $R \& D$ activities, since the latter increase the possibility of having something to offer to firms. Thus, given the inconclusive evidence of Lee, we prefer to assume that the greater the dedication to R\&D activities, the higher the degree of UII will be.

There are some other characteristics related to faculty members linkable to UII. Lee (1996) finds a positive relation between the perceived support of the university and a negative relation between the fear of four possible disadvantages of UII and the support for the objectives of UII. We have not considered the latter, since we understand that they could be subjective factors, caused by those objective characteristics that we explain in the following sub-sections, and thus prevent problems of endogeneity. D'Este and Patel (2005) also include "number of joint publications with industry" and "involvement in patenting activities" in their regressions on the variety of interaction. We consider these to be outputs of academic research that should be explained simultaneously with the degree of UII.

\subsubsection{Faculty members' personal characteristics}

The literature has long studied the idea that certain personal characteristics matter in the process of scientific production. Stephan (1996) sums up various findings on the influence of age, e.g. age is inversely related to research productivity and the acceptance of new ideas, but this relationship is weak. Kotrlick et al. (2002) find from their bibliographical review evidence that the relation between age and research productivity, if any, is negative, but results are not conclusive and their own finding is that it is not determinant. However, since individual research productivity has cumulative features (Merton, 1968), we believe that a better explanatory factor than age could be a measure that takes into account other features such as seniority, e.g. teaching rank or research 
awards. D'Este and Patel (2005) find that age has a negative impact on the variety of interactions, whereas academic status has a positive impact on this variety.

Regarding gender, Kotrlick et al. (2002) reach similar conclusions as those regarding age. Traditional evidence points to higher research productivity in male faculty members, but not conclusively. Xie and Shauman (1998) find that with enough control variables (time between a bachelor's degree and a $\mathrm{PhD}$, marital status, time in classroom teaching, likelihood of securing research funding and research assistance) differences in research productivity disappear.

Both seniority and gender may be related to the degree of UII. In addition, two other personal characteristics may deserve some attention. These are holding an administrative position (in a broad manner, e.g. Dean, department chair or head of a research group.), and having done research abroad. Let us assume that if most faculty members support UII, they will choose administrators who lead them to that goal. Let us also assume that faculty members who do research abroad do so to improve their scientific knowledge. Hence, they will tend to travel to leading scientific countries with more to offer, especially if they are from regions with low absorptive capacity. Some of these leading countries also interact more with industry (e.g. the USA). Therefore, faculty members who do research abroad may find a more interactive culture. Of course, the assumption is arguable. Faculty members may go abroad because they keep ties of a more personal nature with the country chosen, and this would not probably affect UII. In the absence of any better theory, a more cautious statement would be that faculty members who do research abroad may find a different interactive culture. 


\subsection{Do faculty members who tend to interact more with industry do so mainly} with a specific type of firm?

Econometric studies on UII from the point of view of the firm show that some characteristics increase the firms' degree of UII. Here we consider that faculty members will be more likely to engage in UII with firms that have these characteristics. We will first refer to three firm characteristics: size, geographical location and technological level. Then we will focus on one characteristic of firm managers: their academic degree.

\subsubsection{Firm size, geographical location and technological level}

Regarding size, Beise and Stahl (1999) find a positive, significant effect of firm size, measured by the number of employees, on the generation of innovations that could not have been developed without public research by universities. Caloghirou et al. (2000) do not find evidence that the number of employees of firms that have participated in Research Joint Ventures (RJV) of the European Union Framework Programmes (EUFP) influences the degree of participation in R\&D cooperative agreements with universities, but their sales revenues do. Acosta and Modrego (2001) do not find a significant effect of a composite of the number of employees and sales revenue, on the participation in publicly funded concerted projects. Bayona et al. (2001) find a positive, significant effect of dummy variables for large firms on R\&D cooperation. Schartinger et al. (2002) find a significant, negative effect of the proportion of large firms in an economic sector on the frequency of the recourse to contract research. Laursen and Salter (2003) find a significant, positive effect of the number of employees, on the degree of use of knowledge created at universities. In short, four out of six studies that incorporate variables on size find some evidence of a positive relation with the degree of UII. 
Regarding geographical location, Beise and Stahl (1999) do not find a significant effect of the proportion of scientists employed by universities in municipalities less than 100 kilometres away from the municipality of the firm, on the generation of innovations that could not have been developed without public research by universities. Arundel and Geuna (2004) find that compared to four other information sources, proximity effects are greatest for public research organisations. Schartinger et al. (2002) find a (weakly) significant, negative effect of the average of the spatial distance between the departments of a scientific discipline and firms of an economic sector on the frequency of the recourse to contract research. The authors highlight the fact that contract research is the only type of interaction in which geographic distance matters (p. 324). However, this result relies on a low significant effect, at 10\%. Mora-Valentin et al. (2004) do not find a significant effect of the perception of the distance in kilometres and the perception of the time wasted travelling to the partner's address, on the success of the participation in cooperative agreements, both for firms and for public research organisations. That is to say, of these four works that have raised the question, only two find a positive relation between spatial proximity and UII, and the relation is weak. If proximity does not influence UII, it is possible to argue that the determinants of the propensity of firms to interact will have the same effect on interacting inside and outside the region. Nevertheless, based on the fact that the other two studies do not find any evidence against, but simply non-significant, and from the widely accepted association between proximity of academic research and innovation (Jaffe, 1989), we expect that faculty members who interact with industry do so more often with firms inside their region than with those from outside. Non-econometric literature has also found some ground to support the unimportance of geographical proximity when UII takes the form of science parks (Vedovello, 1997). 
There are two forms of studying the technological level of the firm: one is through the intensity of its $\mathrm{R} \& \mathrm{D}$ and another through its belonging to a specific economic sector. Beise and Stahl (1999) do not find a significant effect of firm R\&D intensity on the generation of innovations that could not have been developed without public research by universities, or to belonging to high-tech sectors, but rather to belonging to capital goods sectors. Caloghirou et al. (2000) do not find evidence that the intensity of R\&D expenditure of firms that have participated in RJV of the EU-FP influences the degree of participation in $R \& D$ cooperative agreements with universities, but rather their proportion of scientists to total staff. Acosta and Modrego (2001) find significant, positive effects of several composite variables, relative to R\&D intensity, on the participation in publicly funded concerted projects. Bayona et al. (2001) find positive, significant effects of most of their variables for $R \& D$ capacity on $R \& D$ cooperation, as well as of belonging to intensely technological sectors. Schartinger et al. (2002) find a significant, positive effect of the average R\&D intensity of an economic sector on the frequency of the contract research, although the influence of specific sectors is not significant. Laursen and Salter (2003) find a significant, positive effect of the ratio of $\mathrm{R} \& \mathrm{D}$ expenditure to sales revenue, on the degree of use of knowledge created at universities, as well as belonging to chemistry and machinery sectors. Hanel and StPierre (2006) find a higher probability of collaboration with universities in knowledge based industries and in firms with own in-house R\&D efforts. In general, we can find evidence of a positive relation between technological level and degree of UII.

\subsubsection{University qualifications of firm managers}

In every interactive event, at least two parts are involved. Both choose their respective collaborators, who will decide on a process of communication, in accordance with their own system of signs (code). In the context of UII, the encoding will be made 
up of both academic and commercial elements, the integration of which requires learning from both sides. It is reasonable to assume that the greater the starting knowledge of this code, the more fluent communication will be. In addition, we can assume that the partner with the greatest starting knowledge is the one who has spent most time and has acquired a good reputation in the other's environment. From the point of view of faculty members, the ideal collaborator in the firm will be one with a high degree of academic training.

\section{Data and methodology}

The aim of this section is to explain the methodology followed to test the hypothesis. We have data from the Valencian Community, a Spanish region with a per capita GDP around the national average. Its manufacturing structure is based on microfirms in traditional, low-tech sectors such as toys, textile, shoes, furniture or ceramic tiles. This pattern of specialisation is one of the reasons why the region has several technological weaknesses, as for example a low level of expenditure on R\&D $(0.81 \%$ of GDP in $2002,79 \%$ of the Spanish average and $42 \%$ of EU-15 average) mainly on the part of firms (that financed $32 \%$ of total R\&D in $2001,65 \%$ of the Spanish average and $54 \%$ of EU-15 average), a shortage of financial organisations to fund innovation, and little articulation of institutional links (Fernandez et al., 2001). It therefore fits the description of a region with low absorptive capacity, and we will have to consider this in the interpretation of the results. We follow Cohen and Levinthal's (1990) definition of absorptive capacity: "a limit to the rate or quantity of scientific or technological information that a firm can absorb". To justify the extension of the concept of absorptive capacity from firms to regions, see Niosi and Bellon (2002). Other studies have already approached the issue of regions with low absorptive capacity, e.g. 
Martinez and Pastor (2005), where the authors call them "peripheral regions" and test some of our propositions through a non-econometric approach. They find that larger firms and firms with intermediate R\&D intensity collaborate with the university more than smaller firms and firms with either high or low R\&D intensity.

However, in the Valencian Community, industrial funding of higher education expenditure on research and development has grown to $6 \%$, about the Spanish and the EU-15 average, so the trend of increasing UII is present in the region. For a more detailed characterisation of the Valencian Community as a region with low absorptive capacity, see Azagra et al. (2006). Buesa et al. (2006) also typify it as part of the group of Spanish regions, which show a poor performance in the factors that have an impact on the regional innovation capacity.

We gathered data on faculty members from the five public universities of the Valencian Community through a survey made in 2001. We stratified the population into three categories, according to teaching status: full faculty members, assistant faculty members and associate faculty members. The sample was $10 \%$ of each stratus of the population, or 872 individuals. The questionnaire was sent by the research vicerectorates of each university by electronic mail to the random sample of faculty members. Once filled in, faculty members could return the questionnaire by electronic mail, ordinary mail or fax. After a first stage of spontaneous response, a follow-up team was organised to make telephone contact with faculty members of the sample. This fieldwork took place between 22nd May 2001 and 30th June 2001. We obtained a response rate of $44 \%$, so we were able to build a database with 380 observations. In the following descriptive and regression analysis, teaching scale is always the weighting variable. 
The survey included questions regarding the participation in contracts with firms, according to several firm characteristics. This gave rise to the following dependent variables, whose descriptive statistics appear in Table 1:

* Contracts: usual participation in contracts with firms: 0 ("no") and 1 ("yes"). 29\% of faculty members declare a participation in such contracts. These were the only ones who had to give information about the rest of the variables, so the number of observations falls.

Size: average size of firms with which usual participation in contracts takes place: 0 (smallest firms), 1 (medium-sized firms), 2 (largest firms). The construction of this variable deserves an additional explanation. The survey asked with what type of participation in contracts was most frequent, according to firm size: microfirms and small firms (up to 50 workers), medium firms (51-250 workers), large firms (more than 250 workers). We give correlative categorical values $t=0,1,2$ to each type. Faculty members were allowed to choose up to two types of firms and the answer could take value $\mathrm{x}=1$ if the answer was that participation in contracts with that type of firm was frequent, and $\mathrm{x}=0$ otherwise. Let there be a weighting variable $\pi=0,1$, 2, to the previous types of firm, respectively. Then:

$$
\text { size }=\sum_{t=0}^{2} \frac{\pi_{t} x_{t}}{x_{t}} .
$$

This definition of firm size on employment only is arguable, but we rely on the respondents' perception, not on the name of the firms they interacted with, or any other information that allowed us to identify the companies, so it is not possible to establish a link with other databases to retrieve objective information. However, we made a second survey to Valencian firms where we found that employment is highly correlated with sales and R\&D spending where we studied their relation to the degree of interaction with university (see Azagra, 2007, for details on this 
survey). The distribution of respondents is almost equal between the first two categories ( $45 \%$ and $44 \%$, respectively) with fewer belonging to the third (11\%).

Variables referred to the geographic location of the firm:

Region: frequency of participation in contracts with firms inside the Valencian Community: 0 (“"never/not often"), 1 (“often") and 2 ("very often").

Respondents are divided into almost equal shares in the two first categories (43\% and $40 \%$, respectively) with fewer in the third (18\%).

$>$ Nation: frequency of participation in contracts with Spanish firms outside the Valencian Community: 0 (“never"), 1 (“not often”) and 2 (“often/very often"). Most respondents (43\%) belong to the second category.

World: frequency of participation in contracts with foreign firms: 0 ("never") and 1 ("not often") and 2 ("often"). $42 \%$ of the respondents cooperate with foreign firms.

Technology: most frequent technological level of firms inside the Valencian Community with which usual participation in contracts takes place: 0 ("low"), 1 ("medium") and 2 ("high"). Most respondents belong to the second category (54\%) and fewer to the third $(15 \%)$.

Education: most frequent educational qualifications of the collaborator in the firm: 0 (“with primary or secondary education"), 1 (“further education") and 2 (“doctor"). The immense majority of the respondents belong to the second category $(86 \%)$. Apart from contracts, a dichotomous variable, the rest of dependent variables have a three point scale. The original scale of most dependent variables in this study ranged in a four point scale and the results in terms of significance of the independent variables were identical to those presented, but we opted to shorten the ranks to $0-2$ in order to meet the normality assumption of the distribution of the variables and because doing so 
provided a better fit. The correspondence between the original categories and the point values of the dependent variables appears in Table A. 1 in the appendix. The $0-2$ scale has a certain tradition in the sociology of interaction (e.g. Granovetter, 1970, as quoted in Granovetter, 1973) and it has also been used in the econometric analysis of UII (Arundel and Geuna, 2004). It may be the case that with finer categories the dependent variables are not as well informed as required in an econometric setting.

Table 2 offers the correlation between the previous variables. There is either no significant evidence of correlation or significant evidence of low correlation, so a separate treatment of the variables is adequate. However, we performed a factor analysis, but it was unable to explain more than $20 \%$ of the variance. This further justifies the separate analysis of the variables. This result has some interest, since it recommends not departing from the intuitive vision that large firms show ideal conditions for UII and with small firms the opposite occurs, but from the vision that the types of firm arise from a complex combination of positive and negative characteristics (Molero and Buesa, 1996).

The variables that we wish to explain are of a qualitative and indexed nature. Contracts is binary, so it will be estimated by a probit model. The rest take more than two values, so we perform the estimations by means of an ordered probit model. An alternative approach to the size composite variable was to run probit regressions for each dichotomous component, which allowed for a finer detail. However, the weighted indicator used here leads to identical results and shortens the exposition.

We will estimate initial econometric models on faculty members as a function of the following independent variables, also taken from the survey, whose descriptive statistics appear in Table 3: 
University: univ1, the oldest university (five hundred years old) with the highest scientific prestige, (traditionally) the culture most opposed to UII and the largest number of faculty members (31\%); univ2, a more recently founded university (thirty-five years old), with a technological bias, a certain reputation for active involvement in UII and next in size (29\%); and univ3, a group of the three newest universities (created during the last twenty years), among the smallest and with the least prestige (40\%).

- Disciplines: ens (exact and natural sciences), et (engineering and technology) and ssh (social sciences and humanities). The last acts as a benchmark. The distribution of the three groups is homogenous, around one third of faculty each.

* RDt: proportion of time devoted to R\&D activities (30\%) and not to other academic activities (teaching, other educational activities, administration and other activities).

Senior: one if the faculty is older than forty years, his/her teaching experience has lasted at least ten years, his/her teaching scale is the highest (full professor) and he/she has received at least one Spanish six-year term research award (so-called sexenium). $22 \%$ of respondents fit our definition of senior faculty.

- Gender: 1 if the respondent is a man $(72 \%), 0$ if she is a woman $(28 \%)$.

Administration: 1 if the respondent holds an administrative position within the university $(16 \%)-$ e.g. Dean, department chair or head of a research group-, 0 otherwise $(84 \%)$.

Abroad: length of research abroad: ranging from 0 (the shortest) to 4 (the longest). The average length is between our categories 1 (0-5 months) and 2 (6-11 months). Table 3 refers to the full sample, which we will use for the estimation of the model of the variable contracts. For the rest of the models we use a subsample of faculty members who frequently participate in contracts with firms. It is therefore also of 
interest to offer descriptive statistics, which we do in Table 4. Compared with the full sample, more faculty members who normally participate in contracts belong to univ2 and fewer to univ1 and univ3. The proportion of faculty members in the exact and natural sciences and engineering and technology is higher, while the proportion in social sciences and humanities is lower. Dedication to R\&D is higher for the subsample. In addition, more faculty members are senior, men, holding an administrative position and having done research abroad for a longer period.

\section{Results}

Table 5 shows the results of models reduced after a selection strategy based on minimising the Bayesian Information Criterion (BIC). BIC tends to penalise the entrance of new observations. Hence, final reduced models admit some non-significant variables that, if deleted, incorporate a large number of "don't knows". We divide the results according to our two main questions.

\subsection{What type of faculty member interacts most with firms?}

According to Column 1, the type of university does not significantly affect the probability that faculty members participate in contracts with firms, and in fact, the university dummy variables are not included in the reduced model. This contrasts with the previous descriptive analysis, which seemed to indicate that faculty members of univ2 showed a greater propensity to contract with firms. That result is not robust after the inclusion of other variables or, in other words, although some universities apparently contract more with firms, in reality this is not due to particularities outside the model, e.g. cultural differences.

The effect of disciplines is significant. Thus, the propensity of faculty members to participate in contracts with firms in engineering and technology is the largest. Faculty 
members in exact and natural sciences also contract significantly more than those in social sciences and humanities.

We find it significant that the more time devoted to $R \& D$ activities, the higher probability that faculty members participate in contracts with firms. Compared to Lee's (1996) study, when he analyzed the support for the objectives of the IUE in the case of the USA, our results differ in that the university effect is less important while dedication to $R \& D$ is more important. Of course, it is possible to attribute this to the different geographic contexts, but this may also be due to the fact that Lee analysed attitudes,

which are more likely to be influenced by institutional factors such us university, whereas we study actual UII, which may be influenced more by input factors, such us capacity to offer results from R\&D.

As regards personal characteristics, we find that to be a senior faculty member, to be a man and to hold an administrative position increases the probability of participation in contracts with firms; but not having spent lengthy periods doing research abroad.

Next we analyse the sub-sample of faculty members who usually participate in contracts with firms to find out the type of firms these contracts take place with. Columns 2 to 6 include the estimations. It should be noted that they are all ordered probit models and the $\mu$ parameter is always significant, indicating that the estimation technique is appropriate.

\subsection{Do faculty members who interact most with industry do so mainly with a specific type of firm?}

Given the foregoing results, the expectation is that faculty members in the disciplines of engineering and technology and the exact and natural sciences, who devote most time to R\&D activities, who are senior male faculty members, and who hold an administrative position participate to a greater extent in contracts with large 
technologically advanced firms inside the region, and through collaborators with a higher university degree. The remaining variables - university, length of stay abroadshould not exert a significant effect.

Estimating column 2 at Table 5 allows us to explain the size of firms with which faculty members cooperate most frequently. There is evidence that fulfils the expectations, i.e. faculty members who usually participate in contracts do so mainly with large firms. On one hand, neither university nor length of research abroad have a significant effect on frequency of participation in contracts with larger firms. On the other hand, to be male and to devote more time to $R \& D$ activities increases this frequency. At the 5\% significance level, there is no contradictory evidence that faculty members who contract with firms do so mainly with small firms.

Columns 3 and 4 in Table 5 show the estimations corresponding to the variables with a regional content: column 3 on firms inside the Valencian Community and column 4 on Spanish firms outside the Valencian Community. It will be noted that there are no results on foreign firms since we were not able to fit a significant model.

Concerning column 3, on the one hand, there is some evidence against the expectations, i.e. faculty members who usually participate in contracts do not do so mainly with firms inside the region but, rather, outside the region. On one hand, holding an administrative position does not have a positive influence, as would be expected with the frequency of contracts with firms inside the region, but the influence is, on the contrary, negative. On the other hand, having done research abroad for longer periods is not neutral, as could be expected, but has a positive, significant effect.

Column 4 provides additional evidence against the expectations, since the effect of being male on frequency of contract with firms outside the region has a positive sign, even though we expected it to have a negative sign. In addition, having done research 
abroad for longer periods is not neutral, as could be expected, but has again a positive, significant effect.

Column 5 at Table 5 shows that males and those who hold an administrative position find that the technological level in firms inside the region is low. This type of faculty member interacts more frequently with firms outside the region or less frequently inside the region, which means that they find more technologically advanced firms outside the region. Therefore, there is evidence to fulfil the expectation that faculty members who usually participate in contracts do so mainly with high-tech firms.

Finally, column 6 at Table 5 shows the results on the academic qualifications of the collaborators in the firm. Since the variability of the dependent variable is low, it is more difficult to find significant regressors than in the previous model. In fact, there is only one of these, namely duration of research abroad, and this is only significant at the $5 \%$ level. This means that there is no evidence to fulfil the expectation that faculty members who usually participate in contracts do so mainly with collaborators with advanced academic qualifications. On the other hand, the duration of research abroad, although not expected to be significant, does have a positive effect.

Overall, we find evidence to support the hypothesis that only selected types of faculty members interact with specific types of firms: some faculty members will show higher propensity to engage into UII (those in specific scientific areas, who have more resources for R\&D activities, with a senior status, male and holding an administrative position) and at least some of them (those who have more resources for R\&D activities, male and holding an administrative position) will find it easier to interact with some firms (those of larger size, in science-based sectors). 


\section{Conclusions, limitations and future research lines}

We have tried to contribute to the literature on UII from the side of university by addressing three questions: Do personal characteristics of faculty members matter more than institutional and input factors to engage into university-industry interaction? Do faculty members who interact most with industry do so mainly with a specific type of firm? Is the region a relevant unit of observation for the analysis of university-industry interaction?

Regarding the first question, it may be the case that to favour specific universities will not enhance contracts with firms. Hence, we challenge the view that universities may play a crucial role on UII (Marques et al., 2006; Rasmussen et al., 2006), when personal characteristics are taken into account, i.e. being a senior male faculty members in an administrative position, because they show a higher propensity to contract with firms. We may wonder whether this situation is optimal, e.g., do seniority and holding an administrative position constitute an opportunity or a barrier for the engagement in university-industry interaction? Are gender differences due to preferences or to discrimination? On the issue of gender, there are recent to defend both alternatives. On the one hand, Bilimoria et al. (2006) find that women's job satisfaction derive more from their perceptions of the internal relational supports than the academic resources they receive, whereas men's job satisfaction results equally from both. On the other hand, Sabatier et al. (2006) show that women have to demonstrate higher involvement in different networks in order to be promoted. On the specific case of the Valencian Community, there are some reasons to believe that discrimination is deeply rooted in the culture and it actually makes it more difficult for female academics to gain research awards (sexenia), according to Escolano (2006). Interviews by this author also show that the private sector is more hostile to women, and that female faculty members put 
more emphasis in the intra-institutional dynamics than in the inter-institutional dynamics for their career.

Regarding the second question ("Do faculty members who interact most with industry do so mainly with a specific type of firm?"), we find that two types of faculty members who usually participate in contracts with firms - males and those who hold an administrative position- do so mainly with larger firms outside the region, since they are looking for more technologically advanced firms than they can find inside the region. In turn, a type of faculty member who does not usually participate in contracts those who have done research abroad for longer periods- do so both with firms from inside and outside the region, probably because the firm's technological level does not affect him if he can find a collaborator with a higher academic degree within the firm. Whether this state of things is desirable and the outcome of a conscious strategy will be the subject of further research.

Regarding the third question ("Is the region a relevant unit of observation for the analysis of university-industry interaction?"), a positive answer is speculative but promising. If the unit of observation had been a country, like in most previous studies, we could have found no support for the hypothesis that only selected types of faculty member interact with specific types of firm, because the various regional settings within a country may cancel out differences as the ones we observe. What comes out of the study is that the objective of maximising UII is not necessarily compatible with the goal of maximising the contribution of universities to local economic development.

In any case, these conclusions should only be applied to regions like the one we have analysed, the Valencian Community, i.e. those with a low absorptive capacity. We can see it either as a limitation or as an opportunity to study UII from a less common perspective, not focused, as is normally the case, on high-tech countries. Actually, we 
have contributed to provide some evidence of the delocalisation of UII in regions with a low absorptive capacity, which is common to other less favoured contexts (Adeoti and Adeoti, 2005).

An important limitation of the paper is that, in the absence of any well-founded theoretical approach with the specification of a model, the statistical associations do not provide enough evidence of dependent relationships. Therefore, we should build a theory to introduce optimality criteria in order to provide more robust policy recommendations, in the line of Azagra et al. (2007). The authors formulate a maximisation problem that addresses the importance of incentives to engage into interactive vs. non-interactive knowledge production, to recall that policy action should focus on reputation rather than income stemming out from interaction. For a future line of research, a similar exercise should distinguish types of interactive knowledge production according to the targeted firm. In the meantime, policymakers and university administrators should adopt the policy that the ideal is not so much to maximise UII as to find equilibrium between the different modalities of UII, according to the type of faculty member and the type of firm involved.

There are other ways to widen the scope of this research. First, we could estimate the marginal effects of the discrete choice econometric models to obtain coefficients in the form of elasticities, and thus analyse if changes between categories point in the same direction. Secondly, the survey allows us to distinguish faculty members who devote more than $0 \%$ of their academic time to R\&D activities, and the analysis of this subsample would raise new hypotheses on the influence of different types of $R \& D$, R\&D budget and the share of external funding. Thirdly, our results on the gender of faculty members, administrative position, and having done research abroad require additional evidence, perhaps through interviews. 


\section{Acknowledgements}

I wish to express my gratitude to the Valencian High Consultancy Council in R\&D, for providing the funds to carry out this research. To Ignacio Fernandez de Lucio for entrusting the author with the elaboration of the report on which this work is based. I am also grateful to him and to Antonio Gutiérrez Gracia and Fragiskos Archontakis for working with me in previous analyses of the aforementioned survey. Also to Fernando Jiménez Sáez, for the application of techniques in preliminary analyses that were not necessary to develop and to Mark Boden, for help with the English language of some parts of the document -all remaining errors are mine. Finally, to Jordi Molas-Gallart, for advice to enhance the potential impact of the research and to an anonymous referee, whose comments helped improving the quality of the paper.

The research was performed when the author worked at INGENIO. The acknowledgements should be extended to Paul Desruelle and Pietro Moncada PaternóCastello, for allowing the author continuing the work at IPTS.

\section{References}

Acosta Ballesteros, J., A. Modrego Rico, 2001. Public financing of cooperative R\&D projects in Spain: the Concerted Projects under the National R\&D Plan. Research Policy 30, 625-641.

Acs, Z. J., Audretsch, D. B., Feldman, M. P., 1991. Real effects of academic research: Comment. American Economic Review 82 (1): 363-367.

Adeoti, J., A. Adeoti, 2005. Biotechnology R\&D partnership for industrial innovation in Nigeria. Technovation 25, 349-365.

Arundel, A., A. Geuna, 2004. Proximity and the use of public science by innovative European firms. Economics of Innovation and New Technology 13 (6), 559-580. 
Azagra-Caro, J. M., 2007. The regional dimension of university-industry interaction. H. Folmer, J. Suriñach (eds.), Knowledge Externalities, Innovation Clusters and Regional Development, ch. 9. Cheltenham and Northampton: Edward Elgar, forthcoming

Azagra-Caro, J. M., Archontakis, F., Fernández de Lucio, I., Gutiérrez Gracia, A., 2006. Faculty support for the objectives of university-industry relations versus degree of R\&D cooperation: the importance of regional absorptive capacity. Research Policy 35: $37-55$.

Azagra-Caro, J. M., Aznar-Márquez, J., Blanco, J. M., 2007. Interactive vs. noninteractive knowledge production by faculty members. Applied Economics, forthcoming.

Bayona, C., T. García-Marco, E. Huerta, 2001. Firm's motivation for cooperative R\&D: an empirical analysis of Spanish firms. Research Policy 30, 1289-1307.

Beise, M., H. Stahl, 1999. Public research and industrial innovations in Germany. Research Policy 28 (4), 397-422.

Bilimoria, D., Perry, S. R., Liang, X., Stoller, E. P., Higgins, P., Taylor, C., 2006. How do female and male faculty members construct job satisfaction? Journal of Technology Transfer 31 (3), 355-365.

Buesa, M., Heijs, J., Martínez Pellitero, M., Baumert, T., 2006. Regional systems of innovation and the knowledge production function: the Spanish case. Technovation $26,463-472$.

Bush, V., 1945, reprint 1960. Science, the Endless Frontier: A Report to the President. Washington, D.C.: National Science Foundation. 
Caloghirou, Y., N. S. Vonortas, A. Tsakanikas, 2000. University-industry cooperation in research and development. Organizational Issues in University Technology Transfer, Indianapolis, US), June 9-11.

Cohen, W. M., D. A. Levinthal, 1990. Absorptive Capacity: a new Perspective on Learning and Innovation. Administrative Science Quarterly 35 (1), 128-152.

D'Este, P., P. Patel, 2005. University-industry linkages in the UK: what are the factors determining the variety of interactions with industry. $5^{\text {th }}$ Triple Helix Conference, Turin, Italy), 18-21 May.

Escolano Zamorano, E., 2006. Entre la discriminación y el mérito: Las profesoras en las universidades valencianas. Valencia: Universitat de València.

Etzkowitz, H., Leydesdorff, L., 1996. Emergence of a Triple Helix of UniversityIndustry-Government Relations. Science and Public Policy 23: 279-286.

Fernández de Lucio, I., A. Gutiérrez Gracia, J. Azagra Caro, F. Jiménez Sáez, 2001. Las debilidades y fortalezas del sistema valenciano de innovación. In: M. Olazarán, M. Gómez Uranga (Eds.), Sistemas regionales de innovación. Universidad País Vasco. Freeman, C., 1987. Technology Policy and Economic Performance: Lessons from Japan. London: Pinter.

Granovetter, M. S., 1973. The Strength of Weak Ties. American Journal of Sociology $78(6), 1360-1380$.

Griliches, Z., 1958. Research costs and social returns: hybrid corn and related innovations. Journal of Political Economy 56: 419-431.

Hanel, P., St-Pierre, M., 2006. Industry-University Collaboration by Canadian Manufacturing Firms. Journal of Technology Transfer 31 (4), 485-499.

Jaffe, A. B., 1989. Real effects of academic research. American Economic Review 79 (5), 957-70. 
Kline, S. J., Rosenberg, N., 1986. An overview of innovation. In: R. Landau and N. Rosenberg (eds.): The positive sum strategy: Harnessing technology for economic growth. Washington: National Academy Press: 275-306.

Kotrlick, J. W., J. E. Bertlett, II, C. C. Higgins, H. A. Williams, 2002. Factors associated with research productivity of agricultural education faculty. Journal of Agricultural Education 43 (3), 1-10.

Laursen, K., A. Salter, 2003. Searching low and high: what types of firms use universities as a source of innovation? Research Policy 33, 1201-1215.

Lee, Y. S., 1996. Technology transfer and the research university: a search for the boundaries of university-industry collaboration. Research Policy 25, 843-863.

Lundvall, B. Å., 1988. Innovation as an interactive process: from user-producer interaction to the national system of innovation. In: G. Dosi, C. Freeman, R. Nelson, G. Silverberg and L. Soete (eds.): Technical Change and Economic Theory. Pinter: London.

Mansfield, E., 1968. Industrial Research and Technological Innovation -An Econometric Analysis, New York: Norton.

Mansfield, E., 1991. Academic research and industrial innovation. Research Policy 20: $1-12$.

Marques, J. P. C., J. M. G. Caraça, H. Diz, 2006. How can university-industrygovernment interactions change the innovation scenario in Portugal? -the case of the University of Coimbra. Technovation 26: 534-542.

Martinez-Sanchez, A., A. C. Pastor-Tejedor, 1995. University-industry relationships in peripheral regions: The case of Aragon in Spain. Technovation 15 (10), 613-625.

Merton, R. K., 1968. The Matthew effect in science. Science 159, 56-63. 
Molas-Gallart, J., Salter, A., Patel, P., Scott, A., Duran, X., 2002. Measuring Third Stream Activities. Final Report to the Russell Group to the Russell Group of Universities. SPRU, University of Sussex.

Molero, J., J. Buesa, 1996. Patterns of technological change among Spanish innovative firms: the case of the Madrid region. Research Policy 25, 647-663.

Mora-Valentin, E. M., A. Montoro-Sanchez, L. A. Guerras-Martin, 2004. Determining factors in the success of R\&D cooperative agreements between firms and research organizations. Research Policy 33, 17-40.

Narin, F., Hamilton, K. S., Olivastro, D., 1997. The increasing linkage between U.S. technology and public science. Research Policy 26 (3): 317-30.

Narin, F., Noma, E., 1985. Is technology becoming science? Scientometrics 7 (3-6): 369-381.

Niosi, J., B. Bellon, 2002. The Absorptive Capacity of Regions, Colloque Economie Méditerranée Monde Arabe. Sousse 20-21 September.

Rasmussen, E., Moen, Ø., Guldbransen, M., 2006. Initiatives to promote commercialization of university knowledge. Technovation 26, 518-533.

Sabatier, M., Carrere, M., Mangematin, V., 2006. Profiles of academic activities and careers: Does gender matter? Journal of Technology Transfer 31 (3), 311-324.

Salter, A. J., Martin, B. R., 2001. The economic benefits of publicly funded basic research: a critical review. Research Policy 30: 509-532.

Schartinger, D., C. Rammer, M. M. Fischer, J. Frölich, 2002. Knowledge interactions between universities and industry in Austria: sectoral patterns and determinants. Research Policy 31, 303-328.

Scherer, F. M., 1965. Firm Size, Market Structure, Opportunity and the Output of Patented Inventions, American Economic Review 55: 1097-1125. 
Scott, A., Steyn, G., Geuna, A., Brusoni, S., Steinmueller, E. W., 2002: The Economic Returns to Basic Research and the Benefits of University-Industry Relationships: A literature review and update of findings. SPRU: Report for the Office of Science and Technology.

Stephan, P., 1996. The Economics of Science, Journal of Economic Literature 34 (3), $1199-1235$.

Vedovello, C., 1997. Science parks and university-industry interaction: geographical proximity between the agents as a driving force. Technovation 17 (9), 491-502.

Xie, Y., K. A. Shauman, 1998. Sex differences in research productivity revisited: new evidence about an old puzzle. American Sociological Review 63, 847-70. 


\section{Tables}

Table 1. Sample of faculty members. Descriptive statistics of dependent variables

\begin{tabular}{llllll}
\hline Variable & Mean & $\begin{array}{l}\text { Standard } \\
\text { deviation }\end{array}$ & Minimum & Maximum & $\begin{array}{l}\text { No. of } \\
\text { observations }\end{array}$ \\
\hline Contracts & 0.29 & 0.46 & 0 & 1 & 375 \\
\hline Size & 0.67 & 0.68 & 0 & 2 & 109 \\
\hline Region & 0.76 & 0.74 & 0 & 2 & 108 \\
\hline Nation & 1.03 & 0.75 & 0 & 2 & 101 \\
\hline World & 0.50 & 0.64 & 0 & 2 & 98 \\
\hline Technology & 0.84 & 0.67 & 0 & 2 & 102 \\
\hline Education & 0.97 & 0.36 & 0 & 2 & 103 \\
\hline
\end{tabular}

Table 2. Sample of faculty members. Correlation coefficients of dependent variables

\begin{tabular}{lllllll}
\hline Variable & Size & Region & Nation & World & Technology & Education \\
\hline Size & 1.00 & & & & & \\
\hline Region & 0.09 & 1.00 & & & & \\
\hline Nation & 0.19 & 0.17 & 1.00 & & & \\
\hline World & 0.16 & 0.17 & $\mathbf{0 . 4 0}$ & 1.00 & & \\
\hline Technology & 0.11 & -0.07 & -0.07 & 0.10 & 1.00 & \\
\hline Education & 0.13 & -0.05 & 0.01 & 0.03 & $\mathbf{0 . 2 5}$ & 1.00 \\
\hline
\end{tabular}

Bold print: significance at least at the 5\% level (two-tailed)

Table 3. Sample of faculty members. Descriptive statistics of independent variables

\begin{tabular}{llllll}
\hline Variable & Mean & $\begin{array}{l}\text { Standard } \\
\text { deviation }\end{array}$ & Minimum & Maximum & $\begin{array}{l}\text { No. of } \\
\text { observations }\end{array}$ \\
\hline Univ1 & 0.31 & 0.46 & 0 & 1 & 380 \\
\hline Univ2 & 0.28 & 0.45 & 0 & 1 & 380 \\
\hline Ens & 0.35 & 0.48 & 0 & 1 & 376 \\
\hline Et & 0.33 & 0.47 & 0 & 1 & 376 \\
\hline RDt & 0.30 & 0.19 & 0 & 0.9 & 376 \\
\hline Senior & 0.22 & 0.41 & 0 & 1 & 361 \\
\hline Gender & 0.72 & 0.45 & 0 & 1 & 380 \\
\hline Administration & 0.16 & 0.36 & 0 & 1 & 376 \\
\hline Abroad & 1.29 & 1.38 & 0 & 4 & 373 \\
\hline
\end{tabular}


Table 4. Faculty members who usually participate in contracts with firms. Descriptive statistics of independent variables

\begin{tabular}{llllll}
\hline Variable & Mean & $\begin{array}{l}\text { Standard } \\
\text { deviation }\end{array}$ & Minimum & Maximum & $\begin{array}{l}\text { No. of } \\
\text { observations }\end{array}$ \\
\hline Univ1 & 0.31 & 0.46 & 0 & 1 & 118 \\
\hline Univ2 & 0.38 & 0.49 & 0 & 1 & 118 \\
\hline Ens & 0.44 & 0.50 & 0 & 1 & 116 \\
\hline Et & 0.42 & 0.50 & 0 & 1 & 116 \\
\hline RDt & 0.35 & 0.17 & 0 & 0.8 & 117 \\
\hline Senior & 0.33 & 0.47 & 0 & 1 & 108 \\
\hline Gender & 0.85 & 0.36 & 0 & 1 & 118 \\
\hline Administration & 0.23 & 0.42 & 0 & 1 & 117 \\
\hline Abroad & 1.54 & 1.40 & 0 & 4 & 116 \\
\hline
\end{tabular}

Table 5. Faculty members in the Valencian Community. Determinants of usual participation in contracts with firms and frequency of participation by type of firm and academic degree of firm manager

\begin{tabular}{|c|c|c|c|c|c|c|}
\hline Dependent variable & $\begin{array}{l}1 \\
\text { Contracts }\end{array}$ & $\begin{array}{l}2 \\
\text { Size }\end{array}$ & $\begin{array}{l}3 \\
\text { Region }\end{array}$ & $\begin{array}{l}4 \\
\text { Nation }\end{array}$ & $\begin{array}{l}5 \\
\text { Technology }\end{array}$ & $\begin{array}{l}6 \\
\text { Education }\end{array}$ \\
\hline No. of observations & 347 & 104 & 103 & 98 & 101 & 98 \\
\hline Log likelihood & -173.72 & -95.63 & -100.23 & -99.26 & -94.77 & -37.92 \\
\hline Prob[x2 > value] & 0.00 & 0.03 & 0.03 & 0.00 & 0.01 & 0.00 \\
\hline Independent variable & $\begin{array}{l}\text { Coeff. } \\
\text { (t-ratio) }\end{array}$ & $\begin{array}{l}\text { Coeff. } \\
\text { (t-ratio) }\end{array}$ & $\begin{array}{l}\text { Coeff. } \\
\text { (t-ratio) }\end{array}$ & $\begin{array}{l}\text { Coeff. } \\
\text { (t-ratio) }\end{array}$ & $\begin{array}{l}\text { Coeff. } \\
\text { (t-ratio) }\end{array}$ & $\begin{array}{l}\text { Coeff. } \\
\text { (t-ratio) }\end{array}$ \\
\hline Constant & $\begin{array}{l}-2.24 \\
(-8.61)\end{array}$ & $\begin{array}{l}-1.00 \\
(-2.41)\end{array}$ & $\begin{array}{l}-0.54 \\
(-1.28) \\
\end{array}$ & $\begin{array}{l}-0.27 \\
(-0.73) \\
\end{array}$ & $\begin{array}{l}1.36 \\
(3.88)\end{array}$ & $\begin{array}{l}2.15 \\
(3.03) \\
\end{array}$ \\
\hline Univ1 & & & & & & $\begin{array}{l}-0.50 \\
(-1.21) \\
\end{array}$ \\
\hline Univ2 & & & & & & $\begin{array}{l}-0.76 \\
(-1.65)\end{array}$ \\
\hline Ens & $\begin{array}{l}0.65 \\
(3.11)\end{array}$ & & $\begin{array}{l}-0.14 \\
(-0.36) \\
\end{array}$ & & & $\begin{array}{l}-0.01 \\
(-0.02) \\
\end{array}$ \\
\hline Et & $\begin{array}{l}0.95 \\
(4.47)\end{array}$ & & $\begin{array}{l}0.45 \\
(1.18)\end{array}$ & & & $\begin{array}{l}-0.50 \\
(-0.81)\end{array}$ \\
\hline $\mathrm{RDt}$ & $\begin{array}{l}1.44 \\
(3.28)\end{array}$ & $\begin{array}{l}1.49 \\
(2.16)\end{array}$ & $\begin{array}{l}1.19 \\
(1.65) \\
\end{array}$ & & & \\
\hline Senior & $\begin{array}{l}0.51 \\
(2.68)\end{array}$ & & & & & \\
\hline Gender & $\begin{array}{l}0.54 \\
(2.77)\end{array}$ & $\begin{array}{l}0.75 \\
(2.15)\end{array}$ & $\begin{array}{l}0.20 \\
(0.78) \\
\end{array}$ & $\begin{array}{l}0.88 \\
(2.35) \\
\end{array}$ & $\begin{array}{l}-0.78 \\
(-2.23)\end{array}$ & \\
\hline Administration & $\begin{array}{l}0.45 \\
(2.20) \\
\end{array}$ & $\begin{array}{l}-0.51 \\
(-1.78) \\
\end{array}$ & $\begin{array}{l}-0.53 \\
(-1.97) \\
\end{array}$ & $\begin{array}{l}-0.45 \\
(-1.72) \\
\end{array}$ & $\begin{array}{l}-0.64 \\
(-2.35) \\
\end{array}$ & $\begin{array}{l}-0.76 \\
(-1.88) \\
\end{array}$ \\
\hline Abroad & & & $\begin{array}{l}0.20 \\
(2.24)\end{array}$ & $\begin{array}{l}0.17 \\
(2.00)\end{array}$ & & $\begin{array}{l}0.29 \\
(1.99) \\
\end{array}$ \\
\hline$\mu$ & & $\begin{array}{l}1.35 \\
(7.65) \\
\end{array}$ & $\begin{array}{l}1.19 \\
(7.35) \\
\end{array}$ & $\begin{array}{l}1.26 \\
(7.8) \\
\end{array}$ & $\begin{array}{l}1.59 \\
(8.73) \\
\end{array}$ & $\begin{array}{l}3.62 \\
(9.16) \\
\end{array}$ \\
\hline
\end{tabular}

Bold print: significance at least at the 5\% level (two-tailed) 


\section{Appendix}

Table A.1. Sample of faculty members. Frequency distribution of original categories in the survey and correspondence with point values as dependent variables

\begin{tabular}{|c|c|c|c|c|c|c|}
\hline Variable & Original question & $\begin{array}{l}\text { Original response } \\
\text { categories }\end{array}$ & Point 0 & Point 1 & Point 2 & Total \\
\hline \multirow[t]{5}{*}{ Size } & \multirow{5}{*}{$\begin{array}{l}\text { What type of firms } \\
\text { do you cooperate } \\
\text { with, according to } \\
\text { their size? (tick up } \\
\text { to two choices) }\end{array}$} & $\begin{array}{l}\text { Microfirms (up to } 10 \\
\text { workers) }\end{array}$ & 6 & & & 6 \\
\hline & & $\begin{array}{l}\text { Small firms (11-50 } \\
\text { workers) }\end{array}$ & 42 & & & 42 \\
\hline & & $\begin{array}{l}\text { Medium firms (51-250 } \\
\text { workers) }\end{array}$ & & 35 & & 35 \\
\hline & & $\begin{array}{l}\text { Large firms (more than } \\
250 \text { workers) }\end{array}$ & & & 26 & 26 \\
\hline & & Total & 48 & 35 & 26 & 109 \\
\hline \multirow[t]{5}{*}{ Region } & \multirow{5}{*}{$\begin{array}{l}\text { How frequently do } \\
\text { you cooperate with } \\
\text { firms from the } \\
\text { Valencian } \\
\text { Community? }\end{array}$} & Never & 1 & & & 1 \\
\hline & & Not often & 45 & & & 45 \\
\hline & & Often & & 43 & & 43 \\
\hline & & Very often & & & 19 & 19 \\
\hline & & Total & 46 & 43 & 19 & 108 \\
\hline \multirow[t]{5}{*}{ Nation } & \multirow{5}{*}{$\begin{array}{l}\text { How frequently do } \\
\text { you cooperate with } \\
\text { Spanish firms } \\
\text { outside the } \\
\text { Valencian } \\
\text { Community? }\end{array}$} & Never & 29 & & & 29 \\
\hline & & Not often & & 43 & & 43 \\
\hline & & Often & & & 26 & 26 \\
\hline & & Very often & & & 3 & 3 \\
\hline & & Total & 29 & 43 & 29 & 101 \\
\hline \multirow[t]{5}{*}{ World } & \multirow{5}{*}{$\begin{array}{l}\text { How frequently do } \\
\text { you cooperate with } \\
\text { foreign firms? }\end{array}$} & Never & 59 & & & 59 \\
\hline & & Not often & & 33 & & 33 \\
\hline & & Often & & & 3 & 3 \\
\hline & & Very often & & & 3 & 3 \\
\hline & & Total & 59 & 33 & 6 & 98 \\
\hline \multirow[t]{4}{*}{ Technology } & \multirow{4}{*}{$\begin{array}{l}\text { What technological } \\
\text { degree do you } \\
\text { perceive in the } \\
\text { Valencian firms } \\
\text { you cooperate } \\
\text { with? }\end{array}$} & Low & 15 & & & 15 \\
\hline & & Medium & & 55 & & 55 \\
\hline & & High & & & 32 & 32 \\
\hline & & Total & 15 & 55 & 32 & 102 \\
\hline \multirow[t]{5}{*}{ Education } & \multirow{5}{*}{$\begin{array}{l}\text { What is the most } \\
\text { frequent level of } \\
\text { education of your } \\
\text { interlocutor at the } \\
\text { firm? }\end{array}$} & $\begin{array}{l}\text { Primary or secondary } \\
\text { education }\end{array}$ & 6 & & & 6 \\
\hline & & $\begin{array}{l}\text { Further education } \\
\text { (social sciences, } \\
\text { humanities) }\end{array}$ & & 13 & & 76 \\
\hline & & $\begin{array}{l}\text { Further education } \\
\text { (exact and natural } \\
\text { sciences, engineering) }\end{array}$ & & 76 & & 13 \\
\hline & & Doctor & & & 8 & 8 \\
\hline & & Total & 8 & 89 & 6 & 103 \\
\hline
\end{tabular}

